\title{
POLÍTICA NACIONAL DE DEFESA E PROTEÇÃO DA INFRAESTRUTURA ENERGÉTICA CRÍTICA NO BRASIL
}

\section{lure Paiva ${ }^{1}$}

\section{Introdução}

Os mais diferentes países e regiões do planeta confrontam-se, há muito tempo, com o desafio de se precaver e suplantar situações reais ou iminentes que podem, de alguma forma, perturbar a segurança de sua infraestrutura energética, exigindo a intervenção militar ostensiva e efetiva na vigilância, controle e defesa de tais ambientes. Os casos são os mais variados, incluindo a prevenção e resposta a ações criminosas contra poços e plataformas de exploração de petróleo e gás, ataques a usinas hidrelétricas e nucleares, refinarias, parques eólicos e solares, navios de transporte, portos, tanques, gasodutos, oleodutos, dentre outros, estejam esses localizados na região continental ou oceânica. Os problemas se ampliam e exigem diferentes tipos de respostas na medida em que se observa o crescimento de ataques cibernéticos a sistemas eletrônicos de informação e monitoramento, bem como a ocorrência de eventos naturais de dimensões catastróficas.

A investida de qualquer agente interno ou externo contra a infraestrutura energética crítica ou de reconhecido valor estratégico de um Estado pode causar a interrupção ou o colapso do fornecimento de um dos insumos mais essenciais à manutenção das condições de sobrevivência e desenvolvimento de um país e de sua sociedade de modo geral. E, dentre as inúmeras ações necessárias à proteção da cadeia de produção, comercialização e consumo de energia, emerge como imperativo organizar de forma adequada a defesa de

I Professor Adjunto do Departamento de Relações Internacionais da Universidade Federal da Paraíba (DRI-UFPB) e do Programa de Pós-Graduação em Ciência Política e Relações Internacionais (PPGCPRI/UFPB), com Doutorado em Ciência Política (UNICAMP) e Mestrado em Direito (UFPB). E-mail: iurepaiva@hotmail.com 
todo esse complexo a partir da atuação das forças armadas (Marinha, Exército e Aeronáutica), dada a natureza específica de certas ameaças. O fato de a infraestrutura crítica de energia representar um elemento capital para um país, espera-se que a temática ocupe espaço de destaque na construção da sua estratégia de defesa.

Considerando o contexto ora descrito, este texto apresenta uma análise sobre como a proteção da infraestrutura energética crítica brasileira é tratada no âmbito da política nacional de defesa, buscando com isso compreender melhor como é delineada a segurança do fornecimento de energia no país. A análise desenvolvida neste texto se ocupa de responder três questões básicas: I- Quais são e onde se localizam as principais infraestruturas energéticas críticas brasileiras referentes à cadeia de petróleo, derivados e gás natural? 2Em que medida a proteção das referidas infraestruturas é prevista na política nacional de defesa, em especial, nos principais documentos que tratam do assunto? 3- Como se dá o planejamento de emprego do poder militar brasileiro na prevenção e resposta a ameaças ou ataques contra a infraestrutura relacionada às fontes supracitadas?

Ao examinar a literatura nacional, não parece haver a devida atenção à temática por parte dos estudos referentes à segurança energética no Brasil, ao menos, no que se refere a uma abordagem mais específica e detalhada sobre o que determina a política nacional de defesa sobre a proteção da infraestrutura energética crítica brasileira, salvo algumas raras exceções (Demeterco 20I4; Vicente 20I4). Em geral, o assunto é tratado de forma marginal em meio às questões concernentes aos desafios inerentes à segurança e defesa nacional (Silva 2012; Costa 2009; Hage 2008), às consequências de possíveis conflitos diante de instabilidades no entorno regional (Nasser, Moraes 20I4; Acioly, Moraes 20II), ao aumento dos ilícitos transnacionais (Reis 20II), às disputas sobre a demarcação das zonas marítimas e a soberania sobre os recursos naturais (Silva 20I3; Martins 20IO), à necessidade de proteção das reservas de petróleo e gás na camada pré-sal (Oliveira, Cepik, Brites 2013; Metri 2009), bem como diante da possibilidade de confrontos decorrentes da interferência de potencias extra regionais no Atlântico e na América do Sul (Vidigal 20I4; Thuswohl 2008).

A análise sobre a proteção da infraestrutura crítica desenvolvida neste artigo se insere em questões relativas à dimensão militar da segurança energética, a qual abrange, de modo geral, uma discussão sobre a necessidade de defender, através de ações militares, tanto as reservas como os complexos estruturais energéticos nacionais, contra ameaças que podem afetar o seu perfeito funcionamento e a manutenção dos fatores de subsistência e progresso da sociedade e do país como um todo. A abordagem numa perspectiva mil- 
itarista, ou que a relacione a assuntos de defesa, estará baseada em cenários e análises que envolvem o uso da força ou dos demais aparatos militares, em virtude de disputas relacionadas à energia, ações criminosas, conflitos militares, incidentes operacionais ou eventos naturais, que possam resultar na interrupção parcial ou total do abastecimento energético.

O universo reflexivo e discursivo dos estudos no caso da dimensão militar da segurança energética costuma estar centrado em questões como a identificação das ameaças domésticas ou transnacionais de ataques físicos ou virtuais, decorrentes da ação de atores estatais ou não estatais, contra as reservas ou infraestruturas de energia. De modo análogo, envolve a análise sobre a capacidade ofensiva e defensiva de um país em específico, de um complexo de segurança regional ou da comunidade internacional, contra eventos que podem causar instabilidade ao abastecimento de energia, ou ao lucrativo fluxo de tais recursos ao mercado consumidor mundial. A finalidade maior dessa reflexão está relacionada, em linhas gerais, à manutenção das condições necessárias ao contínuo e adequado provimento de energia no plano nacional, regional e internacional, conforme for a esfera de análise.

No entanto, vale ressaltar que os estudos e práticas sobre a proteção da infraestrutura crítica energética são bem mais amplos, já que os sistemas de engenharia, por exemplo, sofrem falhas de equipamento ocasionais e necessitam de manutenção periódica, o que implica em medidas que envolvem tanto a iniciativa privada como o poder público, conforme o caso (cf. Aradau 20ıо; Farrel et al. 2004). Da mesma forma, segurança energética pode ter diferentes dimensões que vão desde a política e militar à técnica e econômica, destacando, por exemplo, que para os economistas as preocupações são principalmente com os impactos macroeconômicos decorrentes da elevação dos preços da energia e com os perigos das perdas econômicas em razão das possíveis falhas no fornecimento (Ciut 2010; Bielecki 2002).

Este texto busca, portanto, contribuir, de alguma forma, com a superação de uma lacuna na literatura nacional, propondo um estudo específico, sistemático e aprofundando sobre um aspecto específico da proteção da infraestrutura crítica energética brasileira. De modo a cumprir com este intento e responder as questões supracitadas, além desta introdução, o texto possui mais quatro partes. Na próxima seção, o objetivo primordial é o de apresentar alguns marcos conceituais sobre a temática, além de identificar quais são e onde se localizam as principais infraestruturas de produção, comercialização e consumo de energia no Brasil, em especial, aquelas referentes à cadeia do petróleo, derivados e gás natural, isto com o objetivo de se obter um ponto de referência em concreto para a análise de vulnerabilidades e respostas necessárias a sua defesa. 
Na seção seguinte, o escopo principal consiste em verificar de que modo a segurança da infraestrutura energética é efetivamente incorporada e tratada como uma temática de dimensão militar no Brasil, em particular, analisar como a mesma se conforma no âmbito dos dois principais documentos norteadores da política de defesa no país: a Política de Defesa Nacional e a Estratégia Nacional de Defesa. A quarta seção é voltada, precipuamente, à avaliação de aspectos relativos ao planejamento da capacidade ofensiva e defensiva militar do Brasil visando a proteção da infraestrutura relacionada às fontes supracitadas, em meio às principais ameaças (externas) percebidas pelo governo brasileiro e pelos estudiosos da matéria. Por fim, são apresentadas considerações finais com algumas conclusões com o objetivo de sistematizar os resultados alcançados a partir das reflexões realizadas ao longo do texto.

\section{Infraestrutura crítica e segurança energética no Brasil: petróleo, gás e derivados}

O conceito de infraestrutura crítica no Brasil é definido, precisamente, pelo art. $2^{\circ}$ da Portaria $n^{\circ} 2$ do Gabinete de Segurança Institucional da Presidência da República (GSI/PR), de 8 de fevereiro de 2008, que "Institui Grupos Técnicos de Segurança de Infra-estruturas Críticas (GTSIC) e dá outras providências". Segundo a referida portaria "Consideram-se IEC [Infraestruturas Críticas] as instalações, serviços e bens que, se forem interrompidos ou destruídos, provocarão sério impacto social, econômico, político, internacional ou à segurança nacional”. $\mathrm{O}$ art. $3^{\mathrm{o}}$ da citada portaria elenca, entre os incisos I e V, as áreas prioritárias das infraestruturas críticas, sem prejuízo de outras que porventura vierem a ser definidas, figurando nominalmente dentre as que devem ser dada atenção, a infraestrutura que está relacionada à energia. As demais se referem à rede de transporte, água, telecomunicações e finanças.

A supracitada Portaria do GSI/PR, e nenhum outro documento oficial do governo federal, atualmente, estabeleça uma definição precisa sobre in infraestrutura energética crítica no país. Diferentemente do Brasil, verifica-se que Canadá, por exemplo, possui a Estratégia Nacional para a Infraestrutura Crítica (National Strategy for Critical Infrastructure), a qual, dentre outros aspectos, define de forma pontual o significado do referido termo:

A infraestrutura crítica refere-se a processos, sistemas, instalações, tecnologias, redes, bens e serviços essenciais para a saúde, segurança ou bem-estar econômico dos canadenses e do eficaz funcionamento do governo. A 
infraestrutura crítica pode ser autônoma ou interligada e interdependente dentro e entre as províncias, territórios e fronteiras nacionais. As interrupções de infraestrutura crítica podem resultar em perda catastrófica da vida, efeitos econômicos adversos e danos significativos para a confiança da população (Canada 2009).

Com base na definição supracitada, pode-se afirmar que a infraestrutura energética crítica ou de valor estratégico refere-se à cadeia de extração, produção, beneficiamento, transporte, comercialização e consumo de energia de fundamental importância à sobrevivência e ao desenvolvimento do país e de seu povo de modo geral, cuja interrupção ou destruição podem repercutir ainda na esfera internacional (Paiva 20I5, I5I). Contudo, deve-se ressaltar que não é qualquer usina hidrelétrica, estrutura dutoviária, de armazenamento ou de logística que possui valor estratégico, e sim aquelas que realmente têm potencial para causar os impactos citados anteriormente e ter uma repercussão nacional ou internacional (Demeterco 20I4, 07).

Em relação à infraestrutura energética crítica no Brasil que envolve o petróleo, gás natural e seus derivados, pode-se afirmar que grande parte dela está localizada em área marítima ou próximo a mesma. Neste sentido, as estruturas essenciais ora mencionadas incluem, inicialmente, aquelas que estão localizadas em meio às águas atlânticas, e estão relacionadas às bases de extração, explotação e armazenamento de hidrocarbonetos, ambientes físicos peculiares como as rotas marítimas de transporte de recursos energéticos, e, embarcações, dutos e demais meios de escoamento dos produtos fósseis extraídos a partir do mar. Por outro lado, tem-se ainda a infraestrutura situada na zona costeira, a qual está relacionada à geração, processamento, armazenamento, transferência e transporte de recursos energéticos. Nesse caso, pode-se destacar os seguintes complexos estruturais energéticos presentes ou próximas à zona costeira: os polos de refino e armazenamento de petróleo e produção de derivados; as unidades de processamento de gás natural; e os dutos de circulação de petróleo, derivados, gás natural, etanol, solventes e outros.

Um dos pontos de partida para compreender a relação entre infraestrutura energética crítica e extensão territorial atlântica brasileira está no fato de a maior parte das reservas provadas de petróleo e gás natural localizadas em território brasileiro encontrarem-se no Atlântico Sul, respectivamente, cerca de $94,9 \%$ e $88,2 \%$ das jazidas nacionais dessas fontes estão em solo marítimo (ANP 2015, 70-73)². No que se refere à produção de petróleo, dados

2 A Portaria ANP $N^{\circ}$ 9, de 2I/I/2000 define reservas provadas nos seguintes termos: "Reservas de petróleo e gás natural que, com base na análise de dados geológicos e de engenharia, se estima recuperar comercialmente de reservatórios descobertos e avaliados, com elevado grau de certeza, e cuja estimativa considere as condições econômicas vigentes, os métodos operacio- 
oficiais revelam o mesmo papel preponderante do Atlântico Sul, com 92,5\% de tal recurso sendo produzido a partir do mar (ANP 20I5, 75). A produção de gás em campos offshore não alcança os mesmos números se comparados ao petróleo, mas não deixam de ser menos proeminentes, uma vez que deriva do oceano 73,3\% do gás gerado no país (ANP 2015, 82).

Em meio a tal realidade, destaque-se que, de acordo com dados fornecidos pela Diretoria de Portos e Costas da Marinha do Brasil (Brasil 2016), para atender a exploração econômica de hidrocarbonetos derivados do mar, existem 237 complexos estruturais energéticos em águas brasileiras, sendo que I77 estavam em operação e 60 desativadas. Essa infraestrutura refere-se a plataformas fixas, autoeleváveis e de pernas atirantadas, navios sondas e sistemas flutuantes de produção, armazenamento e transferência. Como se pode perceber, a partir do cartograma abaixo, a maior parte delas encontra-se nas bacias presentes ao longo da costa brasileira, dada a sua predominância em tal região.

Cartograma 1 - Bacias efetivas nas áreas da União e com as unidades produtivas em áreas contratadas com recursos descobertos e não descobertos convencionais

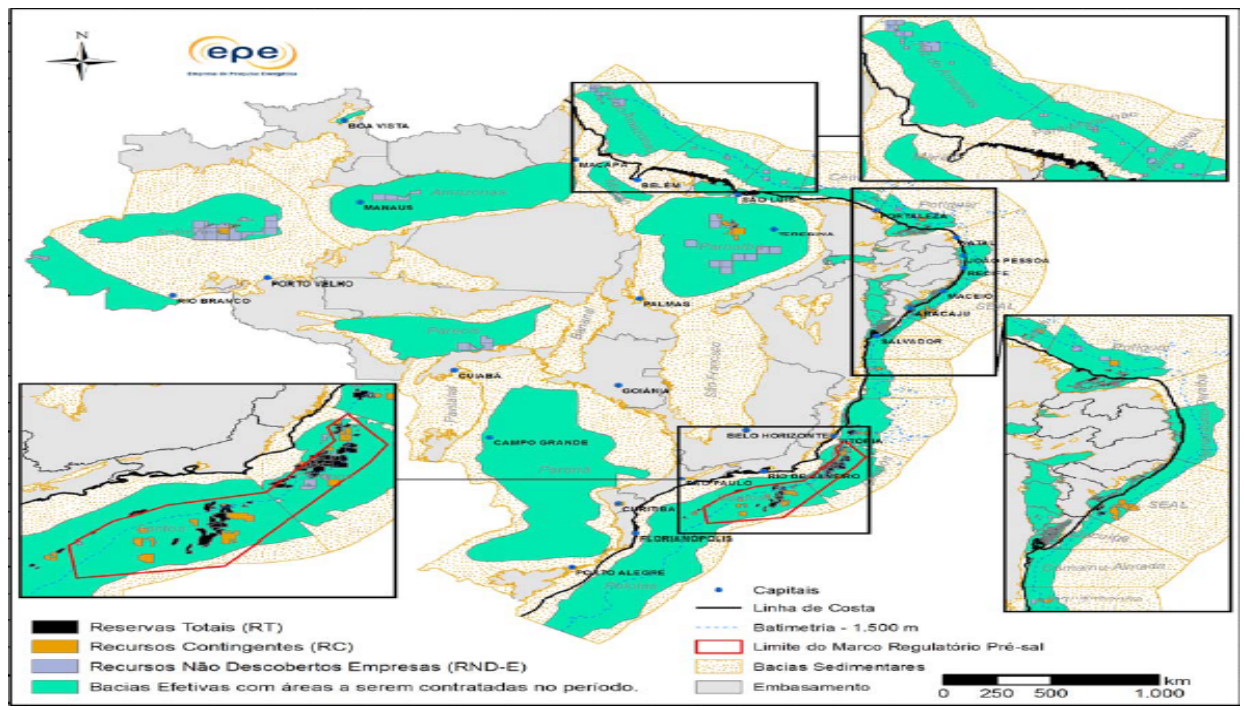

Fonte: Ministério de Minas e Energia e Empresa de Pesquisa Energética (MME, EPE 2015a, 2411

Além dos complexos infraestruturais ligados às reservas de petróleo e

nais usualmente viáveis e os regulamentos instituídos pelas legislações petrolífera e tributária brasileiras". 
gás natural no Brasil localizados na região oceânica, tem-se ainda a infraestrutura situada na zona costeira, a qual está relacionada à geração, processamento, armazenamento, transferência e transporte de recursos energéticos. Nesse caso, pode-se destacar os seguintes complexos estruturais energéticos: os polos de refino do petróleo e de produção de derivados; as unidades de processamento de gás natural; e os dutos de circulação de petróleo, derivados, gás natural, etanol, solventes e outros.

Ao verificar a localização geográfica dos I7 complexos industriais nacionais responsáveis pelo refino do petróleo e a produção de derivados de petróleo no Brasil, verifica-se que a maior parte está situada na zona costeira brasileira ou em cidades que estão muito próximas ao mar ${ }^{3}$. Além de realizarem o processo de refino, tais complexos também são responsáveis pelo armazenamento da maioria do petróleo, derivados de petróleo (gasolina, óleo diesel, óleo combustível, querosene de aviação), intermediários (aguarrás e gasóleo) e etanol que abastecem o país, sejam esses provenientes da produção nacional ou originários do mercado externo. De modo semelhante, ao analisar o local onde estão situados os 15 polos produtores nacionais que respondem pelo processamento de gás natural no Brasil, constata-se que os mesmos também se encontram, predominantemente, na zona litorânea brasileira ${ }^{4}$

O cartograma abaixo permite visualizar perfeitamente como estão próximas à costa brasileira as refinarias de petróleo e os polos de produção e processamento de gás natural, complexos industriais de suma relevância para a segurança energética nacional.

A movimentação de petróleo, derivados e etanol no Brasil também está intimamente relacionada ao oceano Atlântico, em virtude da maior parte dos terminais de armazenamento e dos dutos que transportam tais recursos se localizarem próxima ao litoral brasileiro. Os terminais são um conjunto de instalações adequadamente aparelhado para recebimento, expedição e armazenagem de produtos da indústria de petróleo e demais combustíveis, os quais podem ser classificados em marítimo, fluvial, lacustre e terrestres.

3 As refinarias estão estabelecidas nos estados do Amazonas (Reman), Ceará (Lubnor), Rio Grande do Norte (RPCC), Pernambuco (Rnest), Bahia (RLAM e Dax Oil), Rio de Janeiro (Manguinhos, Reduc), São Paulo (Recap, Replan, Revap, RPBC e Univen), Minas Gerais (Regap), Paraná (Repar) e Rio Grande do Sul (Riograndense e Refap).

4 Os polos de processamento encontram-se nos estados Amazonas (Polo Urucu), Ceará (Polo Lubnor), Rio Grande do Norte (Polo Guamaré), Alagoas (Polo Alagoas), Sergipe (Polo Atalaia), Bahia (Polos Candeias, Pojuca e São Francisco do Conde), Espírito Santo (Polos Cacimbas e Sul Capixaba), Rio de Janeiro (Polos Reduc e Cabiúnas), São Paulo (Polos RPBC e Caraguatatuba) e Paraná (Araucária).

5 A definição foi baseada naquela proposta no sítio internet da Agência Nacional de Petróleo no endereço: <http://www.anp.gov.br/?id=582\#t>. Acesso em: 22 Maio 2014. 
O país dispõe de um total de I.939 tanques, distribuídos em Io8 terminais autorizados, sendo 9 centros coletores de etanol (2I tanques), 56 terminais aquaviários (I.442 tanques) e 43 terminais terrestres (476 tanques). Os terminais aquaviários concentram a maior parte da capacidade nominal de armazenamento $(69,6 \%)$ e o maior número de tanques autorizados $(74,4 \%)$ (ANP,20I5, II3). Embora exista uma diversidade de terminais aquaviários e terrestres no Brasil, pode-se perceber pelo cartograma abaixo que a maioria está localizada na zona costeira brasileira.

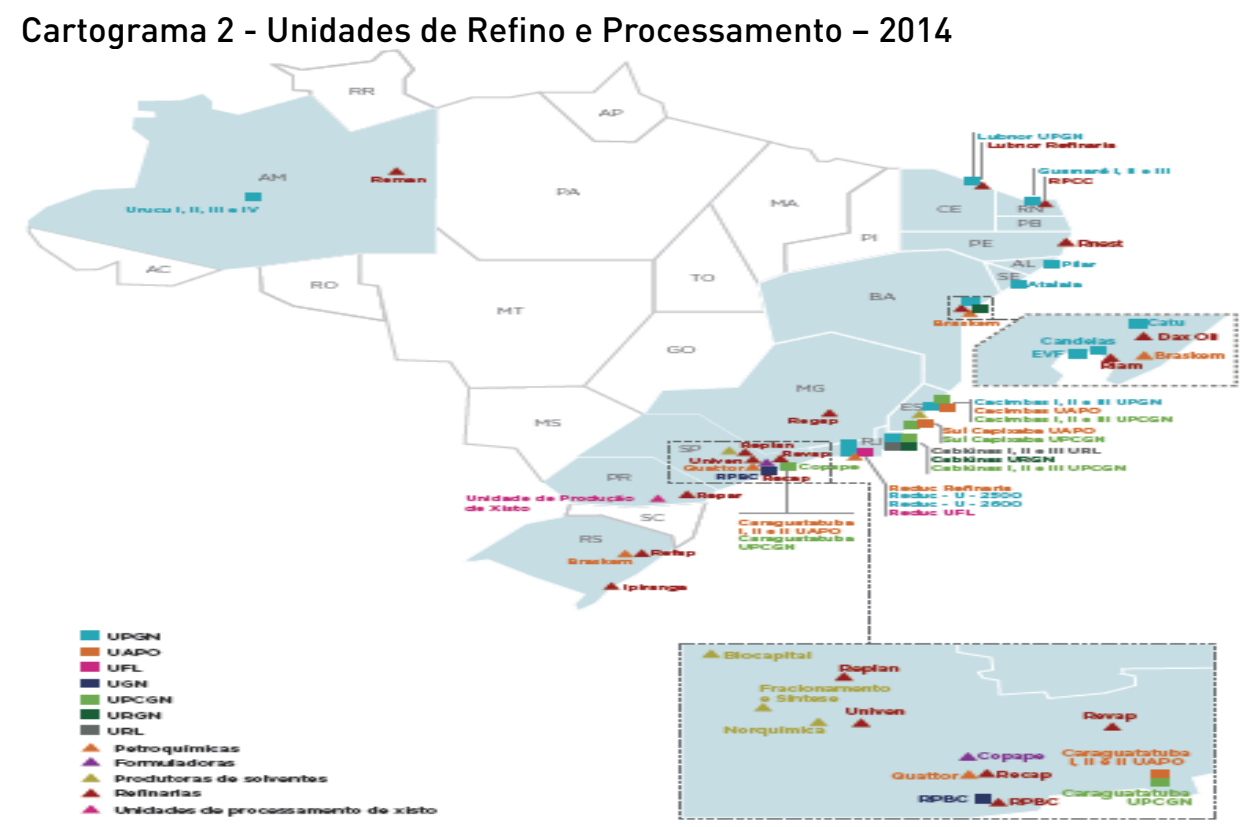

Fonte: Agência Nacional de Petróleo, Gás Natural e Biocombustíveis (ANP 2015, 105)

A propósito da infraestrutura relacionada à movimentação de recursos energéticos, é importante destacar que existe toda uma frota de navios que cruzam as vias marítimas. A navegação de cabotagem, ou seja, entre portos e terminais dentro do Brasil, é responsável por grande parte do transporte de petróleo e gás das plataformas marítimas para as refinarias, distribuição de combustível entre terminais litorâneos, etc. (ANTAQ 20I4). De acordo com os dados da Agência Nacional de Transportes Aquaviários, em meio aos grupos de mercadoria transportados na cabotagem nacional no primeiro semestre de 20I4, destaca-se de modo proeminente a movimentação de "Combustíveis, Óleos Minerais e Produtos”, respondendo em média por $76,5 \%$ da tonelagem movimentada no referido período entre portos brasileiros (ANTAQ 20I4, 4). 
Cartograma 3 - Infraestrutura de Produção e Movimentação de Petróleo e Derivados - 2014
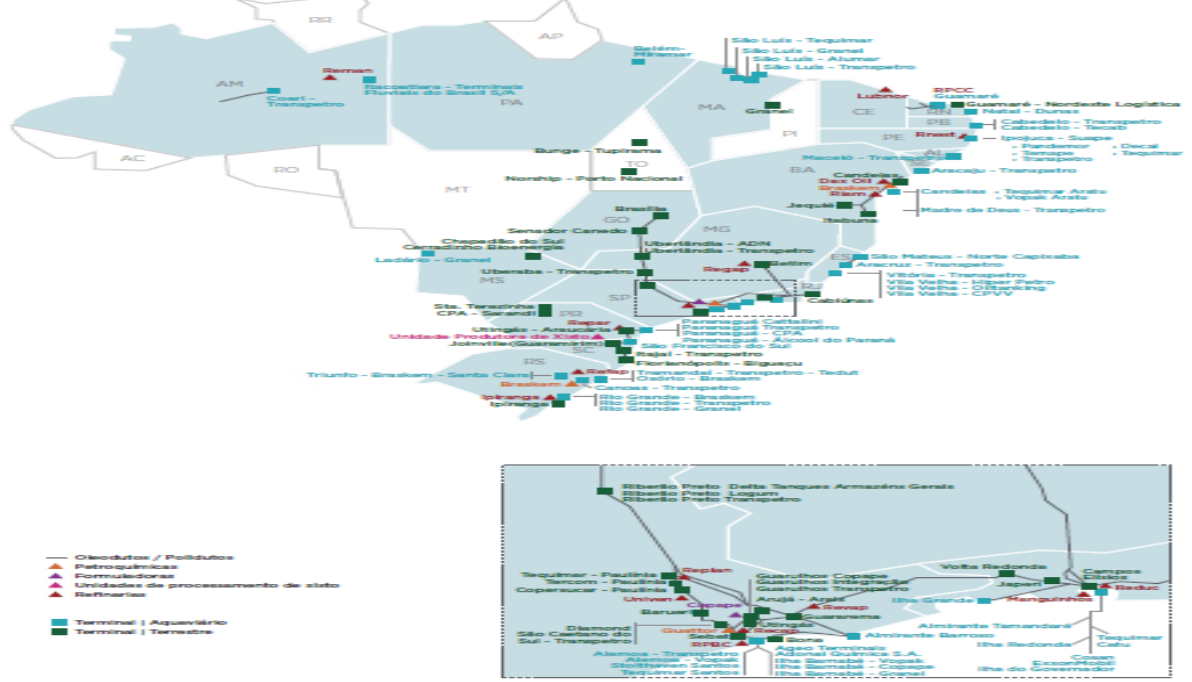

Fonte: Agência Nacional de Petróleo, Gás Natural e Biocombustíveis (ANP 2015, 117)

A infraestrutura relacionada à movimentação de energia no Brasil também inclui os dutos, os quais contribuem para a circulação de petróleo, derivados, gás natural e outros produtos como etanol e solventes. Em 20I4, o país contava com 6oI dutos que se estendiam por I9,7 mil km. A parte mais extensa da malha de dutos é empregada na movimentação de gás natural (gasodutos), cuja extensão é de II,7 mil km, utilizando para isso Iıo dutos. Estas estruturas disponíveis para a circulação de petróleo e derivados (oleodutos), somam ao todo 422 instalações que se estendem por 7,9 mil km. O restante da malha (37 dutos - $76 \mathrm{~km}$ ) é utilizada na movimentação dos demais produtos, como etanol e solventes (ANP 20I5, II6).

O cartograma exibido anteriormente (circulação de petróleo e derivados) e o seguinte (movimentação de gás natural) revelam que parte considerável desses dutos relacionados à infraestrutura energética encontra-se próxima à zona litorânea brasileira, revelando mais uma vez a importância do espaço marítimo do país em razão da necessidade de garantir a segurança energética nacional. 


\section{Cartograma 4 - Infraestrutura de Produção e Movimentação de Gás Natural - 2014}

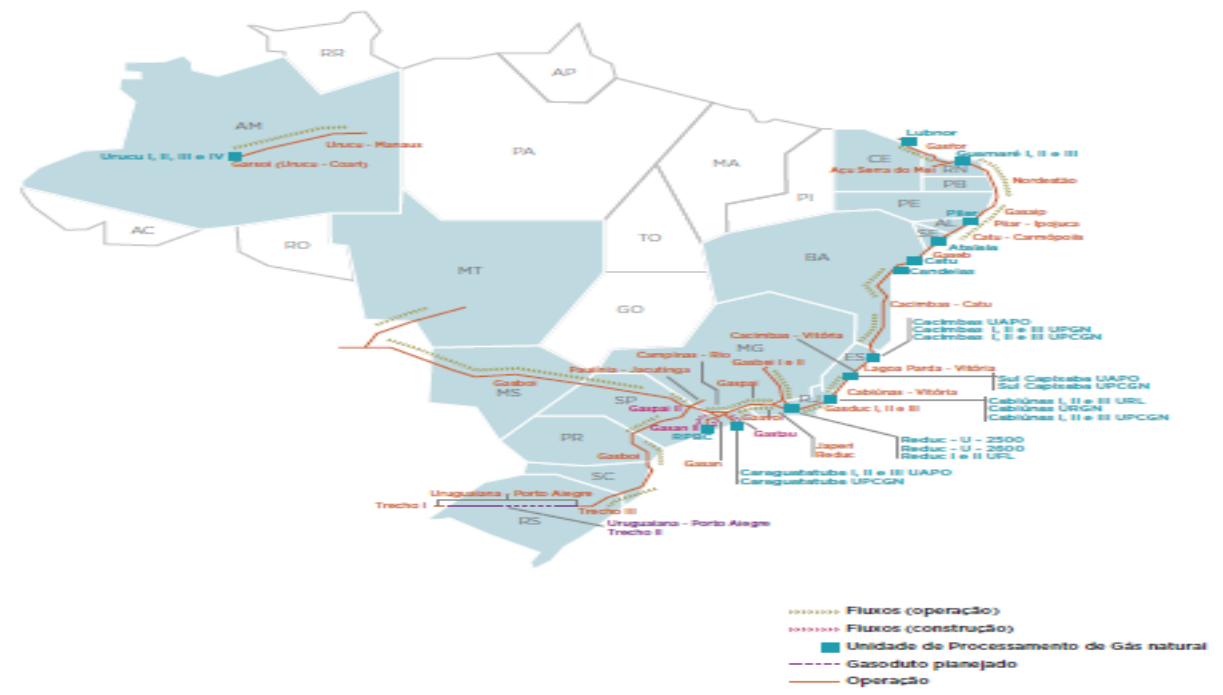

Fonte: Agência Nacional de Petróleo, Gás Natural e Biocombustíveis (ANP 2015, 118).

O Atlântico Sul é igualmente importante para o Brasil por representar a principal rota de entrada e saída de diversos recursos energéticos para o país. A importância dessas rotas marítimas na exportação e importação de petróleo, derivados e gás natural para o Brasil é incontestável, em especial, quando se analisa os dados oficiais que indicam por onde tais recursos circulam para chegar ao país. De acordo com as informações disponíveis no sistema "AliceWeb", do Ministério de Desenvolvimento, Indústria e Comércio Exterior (MDIC), no período que vai de 2005 a 2015 praticamente toda a exportação e importação de petróleo e derivados do Brasil - algo em torno de $99,9 \%$ - ocorreu por meio das vias marítimas atlânticas ${ }^{6}$.

A partir dos dados disponibilizados pelo MDIC, também no sistema “AliceWeb”, entre os anos de 2005 e 2015, as exportações de gás natural brasileiro também são feitas, principalmente, por meio do transporte marítimo7. Embora o volume transportado através das rotas oceânicas não seja equivalente ao da exportação de petróleo e derivados, é indiscutível a sua relevância para a comercialização do gás natural brasileiro no exterior, como se pode afirmar a partir da análise dos dados tabela a seguir.

6 A pesquisa no sistema "AliceWeb" foi realizada com o código “2709" para petróleo e “27Io" para derivados da Nomenclatura Comum do Mercosul.

7 A pesquisa no sistema "AliceWeb" foi realizada com o código "27II" da Nomenclatura Comum do Mercosul. 
Em relação à importação de gás natural, verifica-se que a importância do transporte por via marítima perde espaço. A principal razão é o papel do gás boliviano no atendimento da demanda nacional, que ocorre através de gasoduto terrestre. Entretanto, deve-se perceber que entre 2005 e 2015 , a participação da via marítima na importação de gás natural vem aumentando, tendo em vista, principalmente, o acréscimo das aquisições de GNL no mercado externo, visando atender a demanda crescente do mercado brasileiro.

Tabela 1- Exportação e importação de gás natural no Brasil por via marítima

\begin{tabular}{|c|c|c|c|c|c|c|c|c|c|c|c|}
\hline \multicolumn{12}{|c|}{ EXPORTAC̣ÕES } \\
\hline Ano & 2005 & 2006 & 2007 & 2008 & 2009 & 2010 & 2011 & 2012 & 2013 & 2014 & 2015 \\
\hline $\begin{array}{c}\text { Volume } \\
\text { Total } \\
\text { (106 kg) }\end{array}$ & 100,2 & 25,1 & 34,8 & 4,1 & 11,1 & 4,1 & 60,3 & 247,1 & 78,4 & 75,1 & 1,3 \\
\hline $\begin{array}{c}\text { Via Mar } \\
{[\%]}\end{array}$ & 100 & 100 & 98,7 & 84,6 & 99,8 & 60,5 & 97,5 & 99,92 & 100 & 99,9 & 99,75 \\
\hline \multicolumn{12}{|c|}{ IMPORTAC̣ÕES } \\
\hline Ano & 2005 & 2006 & 2007 & 2008 & 2009 & 2010 & 2011 & 2012 & 2013 & 2014 & 2015 \\
\hline $\begin{array}{c}\text { Volume } \\
\text { Total } \\
\text { (106 kg) }\end{array}$ & 1.061 & 1.756 & 2.107 & 3.714 & 2.359 & 4.037 & 4.529 & 5.959 & 7.997 & 15.286 & 16.856 \\
\hline $\begin{array}{c}\text { Via Mar } \\
{[\%]}\end{array}$ & 7,2 & 10,48 & 11,34 & 12,43 & 21,53 & 34,44 & 24,35 & 33,47 & 39,30 & 40,57 & 44,64 \\
\hline
\end{tabular}

Fonte: Ministério do Desenvolvimento Indústria e Comércio Exterior (sistema "AliceWeb")

Por um lado, a dependência do mercado brasileiro das importações de petróleo, derivados de petróleo e gás natural, exige atenção do governo visando garantir que as vias através das quais tais produtos chegam ao país estejam protegidas, de modo a garantir o abastecimento interno e os meios imprescindíveis ao desenvolvimento nacional. Por outro lado, considerando que as exportações de tais recursos são uma importante fonte geradora de dividendos para a economia brasileira, com tendência de aumento considerável nos próximos anos (em razão das descobertas do pré-sal), trata-se de resguardar as condições necessárias para o adequado aproveitamento de oportunidades de geração de riquezas para o país.

Na próxima seção verificar-se-á em que medida a proteção de toda essa infraestrutura supracitada está presente nos principais documentos que tratam da política nacional de defesa. 


\section{Proteção da infraestrutura energética brasileira de petróleo, gás e derivados na política nacional de defesa}

Em relação à proteção militar da infraestrutura energética crítica ou de valor estratégico no Brasil, no momento não existe legislação e documentos oficiais no âmbito do governo federal brasileiro que tratem, exclusivamente, da temática no âmbito da defesa nacional. No sentido contrário, o setor de telecomunicações já possui considerável referencial político, institucional e conceitual, consolidado em documentos oficiais, dentre os quais pode-se destacar o "Guia básico de orientações ao gestor em segurança da informação e comunicações: versão 2.0” (Brasil 20I6), a "Estratégia de segurança da informação e comunicações e de segurança cibernética da administração pública federal 20I5-20I8: versão I.o" (Brasil 20I5), o "Livro verde: segurança cibernética no Brasil” (Brasil 20I0a), e o "Guia de referência para a segurança das infraestruturas críticas da informação” (Brasil 2oıob).

Contudo, isso não significa que os principais instrumentos de orientação política nacional de defesa desconsiderem a necessidade de garantir a proteção da infraestrutura de reconhecido valor estratégico para o país, incluindo a que está relacionada à energia. Nesse sentido, pode-se destacar as previsões que se encontram na Política de Defesa Nacional e na Estratégia Nacional de Defesa. O primeiro se destaca por ser o documento de mais alto nível do planejamento de defesa nacional, estabelecendo objetivos e diretrizes para o preparo e o emprego da capacidade militar nacional. E, outro, versa sobre a organização e orientação das Forças Armadas para melhor desempenharem sua destinação constitucional e suas atribuições na paz e na guerra.

A Política de Defesa Nacional faz menção à "infraestrutura de valor estratégico" apenas duas vezes, porém não emprega o termo ou traz direcionamentos específicos no sentido que se propõe a análise exposta no presente texto. Num primeiro momento, a PDN usa a expressão quando trata sobre "O ambiente regional e o entorno estratégico", exaltando os benefícios decorrentes de iniciativas visando promover a melhoria da infraestrutura na região sul-americana: "A ampliação e a modernização da infraestrutura da América do Sul podem concretizar a ligação entre seus centros produtivos e os dois oceanos, facilitando o desenvolvimento e a integração" (BRASIL 2005). A segunda menção acontece no trecho em que aborda as políticas e ações que podem contribuir para a consecução dos objetivos da Defesa Nacional, ao manifestar a necessidade de "fortalecer a infraestrutura de valor estratégico para a Defesa Nacional, prioritariamente a de transporte, energia e comunicações" (Brasil 2005). A infraestrutura energética, nesse caso, é considera muito mais como um meio para se promover a defesa nacional, e não propriamente um 
fim a ser alcançado pelas forças militares brasileira.

Contudo, isso não significa que a PDN desconsidere a necessidade de garantir proteção à infraestrutura energética de reconhecido valor estratégico para o país, em especial, aquela presente nas águas ou na área litorânea do Atlântico Sul. No entanto, tal previsão se faz de forma indireta, como se pode observar através da interpretação extensiva de outras passagens do seu texto.

A defesa militar da infraestrutura energética brasileira estaria resguarda pela PDN - nos termos do presente estudo -, ao orientar que o planejamento da defesa nacional deve incluir, prioritariamente, as áreas onde se encontram a maior concentração de poder político, econômico e abundância de recursos. Nesse sentido, menciona, especificamente, as regiões litorâneas e as águas jurisdicionais brasileiras no Atlântico Sul (Brasil 2005). No caso a PDN destaca de modo pontual que nessa área estão as maiores reservas de petróleo e gás nacionais, assim como a principal rota por onde passa quase a totalidade do comércio exterior brasileiro (Brasil 2005). Complementarmente, pode-se destacar que o referido documento aponta enfaticamente que existe neste século a possibilidade de intensificação de disputas sobre fontes de energia e outros recursos naturais escassos, os quais podem tornar-se objeto de interesse internacional e ingerência em assuntos internos de outros países, levando a possíveis cenários de conflito (Brasil 2005).

Em tais circunstâncias, não faz sentido dizer que caberá as Forças Armadas brasileiras proteger apenas os recursos energéticos e as vias de transporte desses bens, e ignorar a defesa da infraestrutura relacionada, já que em caso de conflito ambos estariam, indissociavelmente, sob ameaça dos agentes contendores. As possíveis disputas relativas à escassez mundial de recursos e ao domínio de bens naturais específicos, incluindo os energéticos, consistiriam, portanto, em uma igual ameaça à segurança da infraestrutura nacional relacionada à energia, dada a indissociabilidade das questões no plano da promoção da segurança e defesa nacional. Na condição de elemento imprescindível para o desenvolvimento do país, o governo brasileiro não poderia desconsiderar tal fator como elemento central na conformação da política nacional de defesa, visando proteger, entre outros, os interesses energéticos brasileiros na região do Atlântico Sul.

Diante do que fora exposto, no âmbito da Política de Defesa Nacional, a salvaguarda da infraestrutura energética crítica brasileira no Atlântico através do poder militar nacional decorre, sobretudo, de um debate relativo à proteção de recursos estratégicos e ao domínio de espaços vitais sobre os quais o país deve garantir o exercício de direitos soberanos. Nesse sentido, revela ainda, de forma objetiva, a percepção de que a energia figura como um dos determinantes centrais no jogo de poder e riqueza no âmbito das relações 
internacionais, podendo ser alvo da ganância alheia, advinda de agentes externos. Em razão disto, nesse intricado tabuleiro, é de importância capital para o Brasil, e para qualquer país de modo geral, não apenas a defesa das fontes de energia em si, da aérea onde se encontram e das rotas por onde circulam tais recursos, mas também a proteção de todo complexo infraestrutural relacionado, sem o qual não é possível funcionar toda aquela cadeia, que permite explorar economicamente a energia.

A Estratégia Nacional de Defesa (2008), por outro lado, é bem mais objetiva e enfática quanto à necessidade de proteger a infraestrutura de relevante valor estratégico para Brasil, dentre as quais se destaca de modo especial aquelas relativas à energia. Em primeiro lugar, a Estratégia Nacional de Defesa (END) confirma de maneira categórica que o governo brasileiro deve ter como um dos seus focos a defesa proativa das plataformas petrolíferas que se encontram nas suas águas jurisdicionais (Brasil 2008), as quais, como fora mencionado anteriormente, são responsáveis pela maior parte da produção de petróleo e gás natural no país. Além disso, também estabelece como prioridade a defesa proativa das instalações navais e portuárias brasileiras (Brasil 2008), justamente, onde se encontra grande parte da infraestrutura nacional de armazenamento, transporte e transferência de recursos energéticos do país. No mesmo sentido, destaca ainda a necessidade de estar em "[...] prontidão para responder a qualquer ameaça, por Estado ou por forças não-convencionais ou criminosas, às vias marítimas de comércio" (Brasil 2008), as quais consistem em principal rota de circulação de recursos energéticos no Brasil.

De modo geral, a END também trata da proteção da infraestrutura crítica, incluindo a energética, ao estabelecer o planejamento da distribuição espacial das instalações militares e de quantificação dos meios necessários ao atendimento eficaz das Hipóteses de Emprego das Forças Armadas nacionais. A determinação, nesse caso, é categórica no sentido de “[...] que o Sistema de Defesa Nacional disponha de meios que permitam o aprimoramento da vigilância; o controle do espaço aéreo, das fronteiras terrestres, do território e das águas jurisdicionais brasileiras; e da infra-estrutura estratégica nacional" (Brasil 2008, grifo nosso). A inserção dessa orientação no campo das "hipóteses de emprego" do poder militar brasileiro é especialmente importante na medida em que, diante da indeterminação e imprevisibilidade das ameaças latentes ao país, elege-se a infraestrutura estratégica como objeto prioritário no planejamento da defesa nacional.

Em outra passagem, a proteção da infraestrutura energética de importância vital para o Brasil é, novamente, reconhecida pela END, neste caso, por representar um fator determinante para o desenvolvimento nacion- 
al. Nesse sentido, determina ao Ministério da Defesa que ao planejar a distribuição espacial das Forças Armadas no território nacional priorize, entre outras, "a manutenção de tropas no centro-sul do País para garantir a defesa da principal concentração demográfica, industrial e econômica, bem como da infraestrutura, particularmente a geradora de energia” (Brasil 2008, grifo nosso). O direcionamento das tropas nessa região continental do país acaba incidindo exatamente onde se encontra grande parte da infraestrutura energética que está ligada ao Atlântico Sul - conforme fora demonstrado na seção anterior -, sejam aqueles que se encontram nas águas oceânicas ou na zona costeira brasileira.

A Estratégia Nacional de Defesa estabelece, na sequência, que o incremento do nível de Segurança Nacional deve enfatizar "[...] as medidas para a segurança das áreas de infraestruturas críticas, incluindo serviços, em especial no que se refere à energia, transporte, água e telecomunicações" (Brasil 2008, grifo nosso). Conforme consta na END, o incremento do nível de Segurança Nacional caberá a todas as instâncias do Estado. Entretanto, no caso dos complexos estruturais supracitados a responsabilidade recai sobre os "Ministérios da Defesa, das Minas e Energia, dos Transportes, da Integração Nacional e das Comunicações, e ao trabalho de coordenação, avaliação, monitoramento e redução de riscos, desempenhado pelo Gabinete de Segurança Institucional da Presidência da República (GSI/PR)" (Brasil 2008). Em virtude dessa determinação, entende-se porque a definição do conceito de infraestrutura crítica coube justamente ao Gabinete de Segurança Institucional da Presidência da República, tal qual foi registrado anteriormente.

A constituição dessa rede de proteção tem, inquestionavelmente, como um dos focos a preocupação com a manutenção da segurança energética nacional, dada a condição estratégica que possui. Neste contexto, tanto a Política de Defesa Nacional como a Estratégia Nacional de Defesa orientam o governo brasileiro a estar diligentemente preparado e dispor de meios para responder da maneira adequada às ameaças provenientes de agentes internos e externos, que possam infligir algum tipo de constrangimento aos seus interesses energéticos.

Na seção seguinte verificar-se-á como se dá o planejamento de emprego do poder militar brasileiro na prevenção e resposta a ameaças ou ataques contra a infraestrutura relacionada à cadeia de petróleo, gás e derivados citados anteriormente. 


\section{Estratégias de atuação militar do Brasil na defesa da in- fraestrutura energética nacional de petróleo, gás e derivados}

A Estratégia Nacional de Defesa delineia, de modo específico, como devem ser desenvolvidas as ações visando exercer a vigilância e a defesa das águas jurisdicionais e da zona costeira brasileira, as quais irão repercutir, direta e indiretamente, na proteção da infraestrutura energética crítica brasileira. Nesse sentido, estabelece antes de tudo que o papel principal na defesa desse espaço ficará a cargo da Marinha do Brasil, desenvolvendo suas ações tendo em vista três objetivos: a negação do uso do mar, o controle das áreas marítimas e a projeção de poder (Brasil 2008).

A forma através da qual a Marinha do Brasil deverá implementar tais objetivos, segundo o referido documento, será de forma desigual e conjunta, de modo a responder eficazmente aos desafios que se apresentam (Brasil 2008). De acordo com a END, a prioridade será de garantir os meios para negar o uso das águas que se encontram sob o domínio brasileiro, visando se contrapor a qualquer concentração de forças inimigas que venham a se aproximar do Brasil por via marítima (Brasil 2008). A negação do uso do mar ao invasor é, portanto, considerada o ponto de referência para a organização da estratégia de defesa marítima do Brasil.

A negação do uso do mar ao inimigo é definida pela Marinha do Brasil nos seguintes termos: "Tarefa básica do Poder Naval que consiste em dificultar o estabelecimento do controle de área marítima pelo inimigo, ou a exploração deste controle por meio da destruição ou neutralização de suas forças navais, do ataque às suas linhas de comunicação marítimas e aos pontos de apoio" (Brasil 2007, I68). O intento maior dessa medida é, antes de tudo, impedir que forças inimigas avancem ou permaneçam livremente em águas, terra e espaço aéreo brasileiro. A principal ação nesses casos consiste em impor diferentes obstáculos aos invasores, evitando assim que possam investir de alguma forma contra o país.

Há uma variedade de situações que podem exigir a negação do uso do mar pela Marinha do Brasil, por repercutir negativamente sobre a segurança da infraestrutura energética crítica brasileira no Atlântico Sul. A literatura corrente dos círculos acadêmicos civis e militares costumam mencionar, ao menos, quatro tipos de ameaças (Paiva 20I5, I59-I94). A primeira ameaça são as neotradicionais, que, na realidade, são 'velhas ameaças', as quais decorrem de ações ilícitas como pirataria, terrorismo e tráfico ilegal (Reis 20II). Os relatórios do Escritório das Nações Unidas sobre Drogas e Crimes (UNODC 20I3), por exemplo, apontam precisamente o Atlântico Sul, em especial o Brasil, como uma rota importante para ilícitos relativos ao fluxo ilegal trans- 
nacional envolvendo dinheiro, drogas, armas e pessoas. Durante a operação Amazônia Azul da Marinha, realizada em fevereiro de 20I4, o treinamento contou com a retomada de plataforma petrolífera, considerando que um grupo terrorista queira tomar o referido complexo infraestrutural (Mathias 20I4).

A segunda é a instabilidade dos países que margeiam o Atlântico Sul, na medida em que vicissitudes políticas, econômicas e sociais internas podem vir a transcender as fronteiras e se configurar como ameaça à segurança energética do Brasil. Um foco das preocupações brasileiras é Golfo da Guiné, na costa ocidental da África, uma região próxima das áreas onde se localizam parte considerável da produção de petróleo e gás natural do Brasil. O que pode pôr em risco a produção brasileira de energia, o fluxo de recursos energéticos nas rotas marítimas que cortam a região, bem como toda a infraestrutura crítica relacionada (Amorim 20I3; Fiori, Padula, Vater 20I2; Fonseca 20II).

A terceira ameaça refere-se à contestação da soberania brasileira perante suas águas jurisdicionais no Atlântico Sul, a qual pode se dirigir à possessão exclusiva do Brasil sobre as áreas em que se encontram as fontes energéticas e toda infraestrutura estacionaria e móvel presentes nesse território. O Livro Branco de Defesa (Brasil 20I2c, 45) faz alusão à possibilidade de conflitos em decorrência de disputas que envolvem a delimitação dos direitos de soberania sobre a extensão territorial marítima do Brasil. Nesse particular, destaca que, embora I52 países tenham ratificado a Convenção das Nações Unidas sobre Direito do Mar, ainda há países não aderentes, inclusive grandes potências, o que pode se tornar, no futuro, uma fonte de contenciosos. O questionamento sobre a propriedade brasileira sobre as áreas que circundam a região do pré-sal poderia incitar um conflito (Oliveira; Cepik; Brites $20 \mathrm{I} 3,4)$, algo que, certamente, poria também em risco toda a infraestrutura energética crítica.

A quarta ameaça seria decorrente das ações de potências extra regionais visando preservar seus interesses na zona do Atlântico Sul. No que se refere ao comércio internacional de petróleo “Devido às suas características geográficas e náuticas, a bacia do Atlântico Sul, permite o transporte rápido de grandes volumes comerciais, sobretudo da rota do cabo por onde passam 66\% do petróleo europeu e 26\% norte-americano" (Penha 20II, 222). Esse panorama se configura como uma ameaça à segurança energética brasileira devido às zonas de instabilidade que podem ser criadas, caso os interesses dessas potências extra regionais no Atlântico Sul sejam contrariados.

Conforme previsto na END, a defesa da infraestrutura energética crítica nacional exige também o controle de área marítima, cuja definição também é estabelecida pela Marinha do Brasil nos seguintes termos: "Controle que visa 
garantir certo grau de utilização, ainda que temporário, de áreas marítimas limitadas, estacionárias ou móveis, exercido na intensidade adequada à execução de atividades específicas" (Brasil 2007, 68). A intenção primordial do controle de área marítima é fazer com que a região esteja permanentemente monitorada de modo a manter as condições necessárias para o seu adequado aproveitamento segundo os interesses nacionais. Em tais circunstâncias, o poder naval brasileiro é empregado em ações ordinárias ou extraordinárias que envolvem a vigilância cotidiana do espaço marítimo nacional. Caso seja necessário, a resposta efetiva em caso de perigo real ou eminente será realizada a partir da negação do uso do mar, como fora demonstrado anteriormente.

Em relação à defesa da infraestrutura energética nacional, o controle da área marítima é de grande relevância, principalmente, em tempos pacíficos, e teria como escopo, por exemplo, garantir, a partir do monitoramento das rotas, o fluxo coordenado e ininterrupto do comércio internacional de recursos energéticos para o país. Por outro lado, a vigilância visaria ainda a constante atenção para com os recursos naturais, estacionários e móveis que se encontram nas águas jurisdicionais brasileiras no Atlântico Sul, pertencentes ou não ao país, assegurando assim que a produção nacional de petróleo e gás natural se desenvolva de maneira regular na região. Além disso, as constantes patrulhas e monitoramento também teriam papel relevante na prevenção e contenção de danos ambientais decorrentes de problemas em plataformas oceânicas de extração de combustível fóssil, ou das embarcações que transportam recursos dessa natureza, auxiliando numa resposta mais rápida e efetiva.

Um fator preponderante nessa tarefa é o desenvolvimento do Sistema Brasileiro de Vigilância (SISBRAV) que integrará todos os sistemas de monitoramento e controle do país, entre os quais o Sistema de Gerenciamento da Amazônia Azul (SisGAAz). Este último funcionará como um sistema de monitoramento e controle da segurança marítima e para a proteção do litoral brasileiro. A intenção é tornar o SisGAAz o principal sistema de comando e controle da Marinha, voltado ao gerenciamento das atividades ligadas ao mar que envolvam vigilância, monitoramento, prevenção da poluição, recursos naturais, entre outras. Além disso, tem como finalidade incrementar o conhecimento sobre o ambiente marítimo, e o posicionamento dos meios operativos navais para responder prontamente às crises ou emergências que ocorram no litoral brasileiro (Brasil 20I2c, 7I-72).

As Forças Armadas do Brasil realizam constantemente operações de treinamento, alinhamento de sistemas, testes e exercícios de procedimentos táticos para a defesa das águas jurisdicionais e da zona costeira nacional, que dentre suas finalidades incluem a proteção dos recursos energéticos, da infraestrutura relacionada e das rotas por onde circulam grande parte desses 
bens no país. Nesse sentido, pode-se mencionar a Operação Atlântico, a qual consiste em uma das principais intervenções conjuntas das Forças Armadas na área costeira e oceânica brasileira, cuja terceira versão (realizada em novembro de 20I2) contou com a participação de aproximadamente Io mil militares. De acordo com informações do Ministério da Defesa, as ações integradas incluíram exercícios de proteção da infraestrutura energética crítica nacional, tanto em águas profundas como em regiões litorâneas, tendo como um dos seus focos os portos, refinarias e usinas hidrelétricas e nucleares ${ }^{8}$.

A Operação Amazônia Azul, cuja segunda edição foi realizada em março de 20I5, sob a coordenação do Comando de Operações Navais da Marinha do Brasil, a qual utilizou o maior número de meios e tropas empregados, simultaneamente, em águas brasileiras, e teve como objetivos a intensificação da fiscalização do cumprimento de leis e regulamentos e a repressão a ilícitos de toda ordem. Durante a Operação Amazônia Azul, a Marinha do Brasil realizou, além de outras atividades, exercícios de defesa de portos, terminais petrolíferos e aquaviários, e, com o apoio da Petrobras e da Transpetro, fizeram exercícios na Bacia de Campos, voltados à segurança das plataformas petrolíferas e dos navios que circulam na região9.

Por fim, a proteção da infraestrutura energética crítica nacional pela Marinha do Brasil envolve a projeção de poder, a qual se refere à "Estratégia que se desenvolve por meio da participação militar além-fronteiras, em situações que possibilitem o respeito internacional ao País, por iniciativa própria ou atendendo a solicitações provenientes de acordos externos, visando a dissuadir potenciais agressores e a apoiar os interesses nacionais relacionados com a manutenção da paz internacional” (Brasil 2007, 99). O objetivo dessa estratégia está relacionado à ampliação da capacidade militar marítima do Brasil, de modo que a mesma esteja apta a contribuir na conformação dos interesses nacionais não apenas em seu território, mas também em áreas ou "alvos" externos, exatamente por meio da imposição da força ou a ameaça do seu emprego. Nesse sentido, a Estratégia Nacional de Defesa declara de modo literal que "projeção de poder nas áreas de interesse estratégico" é uma das "capacidades desejadas para as Forças Armadas” do Brasil (Brasil 2008).

No âmbito da segurança energética - incluindo a defesa da infraestru-

8 Informações do site do Ministério da Defesa do Brasil. Disponível em: <http://www.operacoes.defesa.mil.br/web/guest/atlantico-3?p_p_auth=LMPxlyD6\&p_p_id=56\&p_p_lifecycle=o\&p_p_state=maximized\&p_p_mode $=$ view\&p_p_col_id=column-3\&p_p_col_ count=I\&_56_groupId=IOI38\&_56_articleId=53544\#.U5a5M_ldVps $>$. Acesso em: I2 dezembro 2015 .

9 Informações do site da Marinha do Brasil. Disponível em: <https://www.mar.mil.br/9dn/ noticias20I5_mar_resultados_amazonia_azul.html>. Acesso em: 22 abril 2016. 
tura energética nacional - a importância da projeção de poder emerge no instante em que o governo brasileiro concebe a necessidade de agir através da expressão de capacidade militar perante os atores (estatais ou não estatais) que operam na ordem internacional, exercendo-a através de posturas e medidas efetivas, as quais podem gerar condições de cooperação ou conflito em diferentes contextos. As ações militares brasileiras nesse sentido podem ser necessárias no cenário de interdependência e competição que caracterizam o comércio mundial de energia, visando preservar os interesses nacionais em seu próprio território, ou junto a países fornecedores ou consumidores de recursos energéticos. O objetivo do Brasil em tais circunstâncias pode ser desde o estímulo ou reforço do prestígio nacional à limitação do poder de influência de outras nações. No entanto, é importante ressaltar que a Estratégia Nacional de Defesa é particularmente enfática ao orientar que nessa inserção internacional "o Brasil ascenderá ao primeiro plano no mundo sem exercer hegemonia ou dominação” (Brasil 2008, oI).

De acordo com tal previsão, o Brasil deveria dispor de capacidade militar para, em determinada circunstância, advertir ou afastar alguma ameaça. A propósito deste debate, o ex-Ministro da Defesa Celso Amorim (2013) ressaltou a importância do Programa de Desenvolvimento de Submarinos (Prosub), criado em 2009, o qual proporciona ao Brasil a possibilidade de construir submarinos, inclusive de propulsão nuclear, o que leva o país a um outro patamar nas relações internacionais. Entretanto, tudo isso tem um custo, o qual geral como consequência o aumento da visibilidade internacional do país e a imposição de desafios de maior monta para o governo e a sociedade brasileira. A projeção de poder não seria, propriamente, um absurdo, mas algo até desejável, porém há de se perceber que se trata "[...] das tarefas mais complexas e caras para uma Marinha, pois implica não apenas num Corpo de Fuzileiros Navais em permanente prontidão [...], mas navios de grande porte e algum tipo de navio- aeródromo" (Bertonha 2009 25).

Diante de algumas incertezas, não é um absurdo afirmar que o protagonismo energético brasileiro, ou outra razão qualquer, pode levar a antagonismos em tempos vindouros, o que não significa dizer que o país deva se transforma, de toda e qualquer forma, numa máquina de guerra, mas estar preparado para proteger os interesses nacionais na região do Atlântico Sul. A procura por recursos energéticos nessa área, por exemplo, pode ultrapassar a disputa econômica, tornando-se um "jogo" que pode envolver a projeção de poder militar, de modo a conquistar posições privilegiadas junto aos mercados fornecedores de energia entre os países que se encontram na região. Deste ponto de vista, considerando tanto a proteção da infraestrutura energética crítica do Brasil como a segurança nacional como um todo, o Atlân- 
tico Sul "[...] deve ser visto como um importante meio de projeção de poder, e de defesa e segurança dos territórios dos países situados nos seus dois lados, exigindo uma presença ativa destes países, que seja capaz de fazer respeitar seus direitos e interesses" (Fiore, Padula, Vater 20I2, I33-I34).

Ao estabelecer ações efetivas para o avanço de forças hostis, a negação do uso do mar, o controle de área marítima e a projeção de poder acabam, portanto, sendo de fundamental importância para ativa e concreta segurança energética brasileira, já que aprimora a rede de proteção da complexa cadeia nacional de energia que se encontra no Atlântico do Sul (incluindo plataformas, navios sondas e sistemas flutuantes de produção, armazenamento e transferência) e a infraestrutura energética localizada na zona costeira (terminais portuários de transferência/armazenamento, dutos, gasodutos, refinarias etc.).

\section{Considerações finais}

As questões que se decidiu confrontar no estudo ora realizado sobre a infraestrutura energética crítica ou de valor estratégico para o Brasil permitem chegar a algumas conclusões que merecem ser destacadas e apresentadas de forma pontual, de modo a compreender de modo apropriado os cenários e desafios específicos com os quais o governo, a sociedade e demais atores nacionais precisam estar atentos, visando a estabelecer estratégias para o desenvolvimento sustentável do país ao longo dos anos.

Uma das conclusões a serem destacadas, inicialmente, é a de que a proteção da infraestrutura energética de valor estratégico para o Brasil está relacionada às discussões sobre segurança e defesa nacional. De acordo com as análises realizadas, a proteção da infraestrutura brasileira relativa à energia é concebida como uma questão de segurança na medida em que é identificada como um fator determinante para a preservação da soberania nacional e integridade territorial, para a promoção dos interesses nacionais, livre de pressões e ameaças, assim como elemento que garante aos cidadãos brasileiros o exercício dos seus direitos e deveres constitucionais. Por outro lado, trata-se de uma questão relativa à defesa nacional porque a segurança de tais complexos exige, entre outras iniciativas, um conjunto de medidas e ações do Estado, com ênfase na expressão militar, contra ameaças preponderantemente externas, potenciais ou manifestas, que visam garantir, igualmente, a proteção do território, da soberania e dos interesses nacionais. Esta percepção sobre o enquadramento da proteção da infraestrutura energética crítica no Brasil como uma questão de segurança e defesa nacional também deriva e 
está em perfeita sintonia com a definição dada às referidas temáticas na PDN (Brasil 2005).

A segunda conclusão a ser destacada é a de que a análise realizada ao longo deste texto evidenciou que o Atlântico Sul e a região litorânea do Brasil são áreas, particularmente, importantes para a segurança energética brasileira, não apenas por estarem localizadas nesses espaços as principais reservas nacionais de petróleo e gás natural, mas também, e não menos importante, pelo fato de estar ali localizada a maior parte da infraestrutura crítica relacionada à produção, comercialização e consumo de tais recursos no país. Nas águas jurisdicionais brasileiras encontram-se os complexos essenciais à exploração econômica de hidrocarbonetos, tais como plataformas fixas, autoeleváveis e de pernas atirantadas, navios sondas e sistemas flutuantes de produção, armazenamento e transferência de extração, bem como oleodutos e gasodutos. Já na zona costeira pode-se destacar os complexos industriais de refino do petróleo, de produção de derivados e os polos produtores e de processamento de gás natural no Brasil, além de vários complexos dutoviários, portos e terminais de recebimento, expedição e armazenagem de diversos recursos energéticos que abastecem a inúmeras regiões do país.

A investida de qualquer agente inimigo a partir do Atlântico Sul, pode ter como consequência a perda do controle brasileiro sobre a principal região produtora de energia fóssil do país e a destruição de parte relevante da infraestrutura energética nacional, causando assim interrupção do fornecimento de recursos essenciais de que o país necessita seja para garantir a sua sobrevivência e seu desenvolvimento de modo geral, como para manter sua "máquina de guerra". Em todas essas circunstâncias, percebem-se os riscos aos quais podem estar expostos os interesses energéticos do país, caso não se dê a devida atenção ao papel que as forças armadas devem desempenhar na região oceânica sob o domínio do Brasil, e no seu entorno estratégico.

A terceira conclusão a que se chegou refere-se à avaliação sobre a inserção da proteção da infraestrutura energética de valor estratégico para o Brasil nos principais documentos que orientam a política de defesa nacional, especificamente, na Política de Defesa Nacional (2005) e na Estratégia Nacional de Defesa (2008). De modo geral, pode-se afirmar que tais documentos registram, objetivamente, a preocupação com a possibilidade de conflitos internacionais por recursos escassos, incluindo a energia, e outras ameaças externas que podem incidir sobre a segurança energética nacional. Diante disso, destacam a necessidade de defender, através das forças armadas, as rotas comerciais, as fontes e infraestruturas energéticas nacionais, contra ameaças que podem afetar diretamente o abastecimento doméstico. Uma análise geral permite asseverar sobretudo que a política defesa em vigor no Brasil inclui 
como um de seus objetivos atender o imperativo de manter o contínuo provimento de energia no país, considerando-a ainda como uma questão prioritária.

De modo mais específico, pode-se dizer que a PDN não faz menção direta à proteção da infraestrutura energética crítica do país, o que não significa que ignore a questão. A defesa militar de tais complexos estaria garantida pela PDN na medida em que o emprego do poder militar ofensivo e defensivo nacional incide sobre a proteção de recursos estratégicos e o domínio de espaços vitais onde se encontram, incluindo, especificamente, as regiões litorâneas e as águas jurisdicionais brasileiras. Em contrapartida, a END é contundente quanto à necessidade de proteger a infraestrutura energética de relevante valor estratégico para Brasil, com orientações diretas sobre à defesa proativa das plataformas petrolíferas, das instalações navais e portuárias, bem como a salvaguarda do complexo produtivo gerador de energia de modo geral, incluindo aquelas localizadas na área do Atlântico Sul.

Por fim, a quarta conclusão decorrente da análise ora realizada identificou que cabe a Marinha do Brasil o papel precípuo de proteger, controlar e vigiar do complexo infraestrutural energético nacional que se encontra na extensão territorial marítima brasileira no Atlântico Sul. As ações, nesse sentido, incluem a negação do uso do mar, o controle das áreas marítimas e a projeção de poder. Vale ressaltar ainda que a posição do Brasil sobre a dimensão militar da segurança energética nacional é a de provedor de segurança, não admitindo a possibilidade de delegar a outros países tal missão, nem tão pouco tem a pretensão de figurar como mero espectador na conjuntura estratégico-militar na região.

Um aspecto derradeiro a ser enfatizado, ainda no âmbito da quarta conclusão, é que a repercussão das ações militares para a manutenção do abastecimento energético brasileiro repercute em outras questões de interesse nacional, tais como: a promoção da política externa (cooperação na área de defesa com os países lindeiros), a proteção do meio ambiental (contenção de danos decorrentes de problemas em plataformas petrolíferas), o desenvolvimento comercial marítimo (proteção dos portos e das rotas marítimas), a geração de tecnologia, emprego e renda (impulsionada pela indústria brasileira de defesa). 


\section{REFERÊNCIAS}

Abreu, Guilherme Mattos de. 2007."A Amazônia Azul: O Mar que nos Pertence." Cadernos de Estudos Estratégicos (Centro de Estudos Estratégicos da Escola Superior de Guerra - Brasil), 6: I7-66.

Acioly, Luciana; Moraes, Rodrigo Fracalossi de. 20II. Prospectiva, Estratégias e Cenários globais: Visões de Atlântico Sul, África Lusófona, América do Sul e Amazônia. Brasília: IPEA, 20II.

Amorim, Celso. 2013. Pirataria e terrorismo na África podem afetar Brasil, diz Amorim. Interview with BBC Brazil. Available at <http://www.bbc. co.uk/portuguese/noticias/2013/05/130502_amorim_entrevista_ pai_jf.shtml> Acessed 5 January 2016.

ANP (Agência Nacional do Petróleo, Gás Natural e Biocombustíveis). 2015. Anuário estatístico brasileiro do petróleo, gás natural e biocombustíveis: 20I5. Rio de Janeiro: ANP.

ANTAQ (Agência Nacional de Transportes Aquaviários). 20I4. Panorama da Navegação Marítima e de Apoio: Informativo Semestral - oI/20I4. Brasília: ANTAQfoI4.

Aradau, Claudia. 20ıо. "Security That Matters: Critical Infrastructure and Objects of Protection" Security Dialogue, 4I: 49I-5I4.

Bertonha, João Fábio. 2009. “Uma política de defesa nacional”, Meridiano 47 I03: 24-28.

Bielecki, J. 2002. "Energy security: is the wolf at the door?" The Quarterly Review of Economics and Finance, 42: 235-250.

Brasil. (Presidência da República. Casa Militar. Departamento de Segurança da Informação e Comunicações). 20I6. Guia básico de orientações ao gestor em segurança da informação e comunicações: versão 2.0. Brasília: Presidency of the Republic.

20I5. (Presidência da República. Gabinete de Segurança Institucional, Secretaria-Executiva, Departamento de Segurança da Informação e Comunicações). Estratégia de segurança da informação e comunicações e de segurança cibernética da administração pública federal 2015-2018: versão I.o. Brasília: Presidency of the Republic.

2005. Política de Defesa Nacional. Decreto $n^{0} 5.484$, de 30 de junho de 2005. Accessed I2 February 20I6. <http://www.planalto.gov.br/ccivil_03/_Ato2004-2006/2005/Decreto/D5484.htm>.

.2008. Estratégia Nacional de Defesa. Decreto $n^{0} 6.703$, de I8 de dezembro de 2008. Accessed I2 February 20I6. <http://www.planalto.gov.br/ 
ccivil_03/_ato2007-2010/2008/Decreto/D6703.htm>.

. 2012c Livro Branco de Defesa Nacional Accessed I2 February 2016.<http:// www.defesa.gov.br/projetosweb/livrobranco/lbdndigital/\#/o>.

20Ioa Livro verde: segurança cibernética no Brasil. Brasília: GSIPR/SE/ DSIC

2oıob. Guia de referência para a segurança das infraestruturas críticas da informação. Brasília: GSIPR/SE/DSIC.

2007. (Ministério da Defesa). Glossário das Forças Armadas. Portaria Normativa $\mathrm{N}^{0}$ I96/EMD/MD, de 22 de fevereiro de 2007. 4..

Canada. 2009. National Strategy for Critical Infrastructure.

Caroli, Luiz Henrique. 20ıo. "A Importância Estratégica do Mar para o Brasil no Século XXI”, Cadernos de Estudos Estratégicos, Centro de Estudos Estratégicos da Escola Superior de Guerra (Brasil) - 9: II8-I58.

Ciută, Felix. 20I0. "Conceptual Notes on Energy Security: Total or Banal Security?”, Security Dialogue, 4I(2): I23-I44.

Costa, Darc. 2009. A estratégia nacional e a energia. Centro de Estudos Estratégicos, Leituras. Accessed 20 May 2012.<www.esg.br/uploads/2009/03/ darc5.pdf $>$.

Demeterco, Fernando Antonio. 20I4 "Segurança das Infraestruturas Críticas”, Coleção Meira Mattos - Revista das Ciências Militares, Rio de Janeiro, Jul. ISSN 2316-489i. Accessed 4 May 2016.<http://www.eceme. ensino.eb.br/meiramattos/index.php/RMM/article/ view/ı97>.

Farrell, Alexander E., Zerriffi, Hisham; Dowlatabadi, Hadi. 2004. "Energy infrastructure and security", Annu. Rev. Environ. Resourc., 29: 42I-469.

Fiori, José Luís (Coor.); Padula, Raphael; Vater, Maria Claudia. 2012 A projeção do Brasil na América do Sul e na África subsaariana, e o controle da bacia do Atlântico Sul. Rio de Janeiro: UFRJ - Centro de Gestão e Estudos Estratégicos (CGEE), Se. Research report.

Fonseca, Carmen. 20II. "O Brasil e a Segurança no Atlântico Sul.” Nação e Defesa, No. I28.

Hage, José Alexandre Altahyde. 2008a. Bolivia, Brasil e a Guerra do Gás - As Implicações Políticas da Integração Energética na Estratégia e na Segurança Nacional Brasileira (orientador: Shiguenoli Miyamoto). Thesis (doctorate) - Universidade Estadual de Campinas, Postgraduate Program in Political Science,.

Marinha Do Brasil (Diretoria de Portos e Costas - Gerência de Vistorias, Inspeções e Perícias Técnicas). 2016 Relatório das plataformas, navios sonda, FPSO e FSO. Accessed II March 20I6. <https://www.dpc. 
mar.mil.br/sites/default/files/ssta/gevi/conformidades/plataformas/ Dec_conf_plat.pdf>.

Mathias, José Carlos. 20I4. A Operação Amazônia Azul. NBR, Accessed 2I April 20I4. Interview. Available at: <https://www.youtube.com/ watch?v=5msE5SWDWII $>$.

Metri, Paulo. 2009. "Pré-Sal: riqueza, poder e discórdia." Tensões Mundiais, 5(9): I4I-I65.

Moreira, José Benedito de Barros. 2007. "Apresentação”, Cadernos de Estudos Estratégicos, Centro de Estudos Estratégicos da Escola Superior de Guerra (Brasil) - o6: 8-II.

Oliveira, Lucas Kerr de; Cepik, Marcos A. C.; Brites, Pedro Vinicius. 20I3. Présal e a segurança do Atlântico Sul: a defesa em camadas e o papel da integração sul-americana. In: Seminário Brasileiro em Estudos Estratégicos Internacionais (SEBREEI), Porto Alegre, UFRGS, 2I-23.

Paiva, Iure. 20I5. As dimensões militares, ambientais e econômicas da segurança energética: análise a partir dos desafios e oportunidades do Brasil no contexto internacional. Doctoral thesis (Postgraduate Program in Political Science) - Universidade Estadual de Campinas, Campinas-SP.

Penha, Eli Alves. 20ıı. Relações Brasil- África e Geopolítica do Atlântico Sul. Salvador: Edufba.

Reis, Reginaldo Gomes Garcia dos. 20ıı. Atlântico Sul: um desafio para o século XXI - as velhas ameaças se perpetuam nas novas?. In: ACIOLY, L.; MORAES, R.F. de (Orgs). Prospectiva, estratégias e cenários globais: visões de Atlântico Sul, África Lusófona, América do Sul e Amazônia. Brasília: Ipea, 6I-82.

Silva, Alexandre Pereira da. 2013. "O novo pleito brasileiro no mar: a plataforma continental estendida e o Projeto Amazônia Azul”, Revista Brasileira de Política Internacional, 56 (I): I04-I2I.

Silva, Francisco Carlos Teixeira da. 20I2. Política de defesa e segurança do Brasil no Século XXI: Um esboço histórico. In: Silva Filho, Edison Benedito da; MORAES, Rodrigo Fracalossi de. Defesa nacional para o século XXI: política internacional, estratégia e tecnologia militar.: organizers. - Rio de Janeiro : Ipea,.., 49-82.

Vicente, Elizeu Pereira. 20I4."A proteção de infraestruturas críticas em energia”, Coleção Meira Mattos - Revista das Ciências Militares, Rio de Janeiro, Jul. ISSN 2316-489i. Accessed 4 May 20I6. <http://servweb.eceme. ensino.eb.br/meiramattos/index.php/RMM/article/view/ig6/165>.

Thuswohl, Maurício. 2008. EUA reativam IV Frota e preocupam dirigentes 
da AL. Carta Maior, Accessed 8 July 2014.

http://www.cartamaior.com.br/?/Editoria/Internacional/EUA-reativam-IVFrota-e-preocupam-dirigentes-da-AL/6/14205>.

UNODC (Escritório das Nações Unidas sobre Drogas e Crimes). 20I3. World drug report 2013. Accessed 20 February 20I4.<https://www.unodc. org/documents/lpo-brazil//Topics_drugs/WDR/2013/PT-Referencias_BRA_Portugues.pdf $>$.

Vidigal, Carlos Eduardo. 20I4. "As Malvinas e o petróleo: perspectivas". Boletim Meridiano 47 I5(I43): I9-27.

\section{RESUMO}

O estudo desenvolvido neste texto tem como objetivo principal apresentar uma análise sobre como a proteção da infraestrutura crítica do setor de energia é tratada no âmbito da política nacional de defesa, de modo a compreender melhor como é delineada a dimensão militar da segurança energética no Brasil. Com o intuito de alcançar tal objetivo, procura-se, inicialmente, identificar quais são e onde se localizam as principais infraestruturas energéticas críticas brasileiras referentes à cadeia de petróleo, derivados e gás natural. Em seguida, verifica-se em que medida a proteção dos referidos complexos estruturais é prevista na política nacional de defesa, em especial, nos principais documentos que tratam do assunto no país. Por fim, observa-se como se dá o planejamento do poder militar ofensivo e defensivo brasileiro na prevenção e resposta a ameaças contra a infraestrutura relacionada às fontes supracitadas.

\section{PALAVRAS-CHAVE}

Política nacional de defesa; Segurança energética; Infraestrutura crítica.

Recebido em 14 de Julho de 2016. Aceito em 25 de Novembro de 2016. 